\title{
SEMI KUASA TITIK DI DALAM LENGKUNGAN HIPERBOLA
}

\author{
Irma Fitri ${ }^{1}$, Mashadi ${ }^{2}$, Hasriati $^{3}$ \\ ${ }^{1}$ Fakultas Tarbiyah dan Keguruan, UIN Sultan Syarif Kasim Riau \\ 2,3Fakultas Matematika dan Ilmu Pengetahuan Alam Universitas Riau \\ irmafitri@uin-suska.ac.id
}

\begin{abstract}
Abstrak. Kuasa titik tidak hanya dibahas pada lingkaran, tetapi kuasa titik juga dapat ditentukan dari irisan kerucut lain, yaitu hiperbola. Pada tulisan ini dibahas mengenai cara menentukan semi kuasa titik terhadap hiperbola yang berada di dalam lengkungan hiperbola dengan menggunakan persamaan garis kutub hiperbola dan jarak dua titik.
\end{abstract}

Kata Kunci: Kuasa titik, semi kuasa titik, hiperbola.

\begin{abstract}
The power of point not only discussed in the circle, but it can also be determined from other conic sections, namely hyperbola. In this thesis discussed about how to determine the semi power of point which is outside and inside the hyperbola arches use the polar line equation of hyperbola and the distance between two points.
\end{abstract}

Keywords: power of point, semi power of point, hyperbola.

\section{Pendahuluan}

Matematika merupakan mata pelajaran yang luas cakupannya dan wajib diajarkan di kurikulum tingkat sekolah. Uno menyatakan bahwa Matematika mempunyai cabang-cabang antara lain Aritmetika, Aljabar, Geometri, dan Analisis [4]. Geometri adalah salah satu cabang ilmu yang mempelajari antara lain tentang titik, garis, sudut, dan bidang. Darsono menyatakan bahwa kata geometri berasal dari bahasa Yunani yaitu geo yang artinya bumi dan metro yang artinya mengukur [1]. Secara umum ruang lingkup geometri adalah mengenai lingkaran, garis dan sudut, bangunbangun datar seperti segitiga dan segiempat, bangun-bangun ruang seperti kubus, balok, prisma, dan bola, kesimetrian, kesebangunan, kekongruenan, geometri analitis, dan sebagainya. Jadi, geometri adalah cabang ilmu Matematika yang berkenaan dengan titik, garis, bidang dan ruang.

Dalam pengajaran Matematika, geometri merupakan bidang yang memiliki banyak materi yang bisa dikembangkan terutama pada sekolah menengah. Geometri penting untuk dipelajari karena berpola deduktif dan efektif membantu penyelesaian masalah dari cabang Matematika serta mata pelajaran lainnya. Salah satu materi yang dipelajari pada geometri adalah kuasa titik. Pada umumnya kuasa titik yang dipelajari adalah kuasa titik pada lingkaran. Kuasa titik terhadap lingkaran merupakan kuadrat jarak antara titik itu ke titik singgung dari garis pada lingkaran.

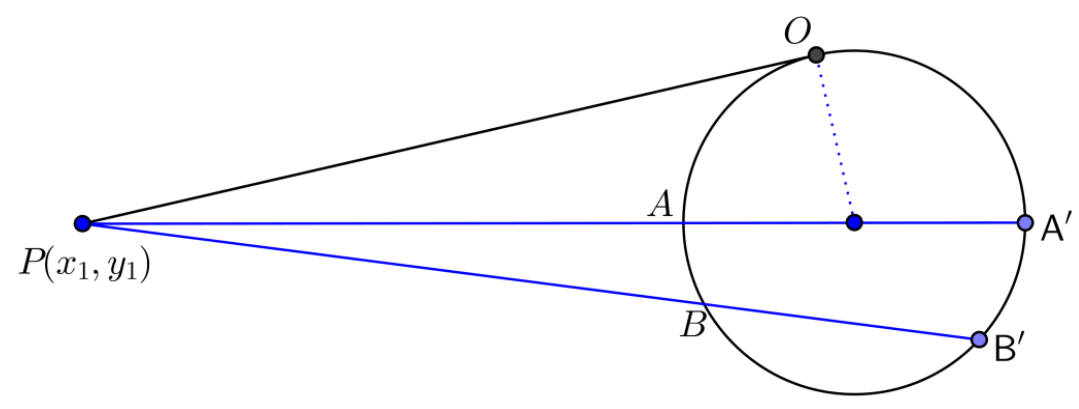

Gambar 1: Kuasa titik terhadap lingkaran 
Jika $P$ di luar lingkaran $L$ maka dapat dibuat banyak garis sehingga memotong $L$ di $A$ dan $A^{\prime}$, $B$ dan $B^{\prime}$, dan seterusnya, serta menyinggung $L$ di $O$. Perhatikan Gambar 1 .

Jika titik $P\left(x_{1}, y_{1}\right)$ dan sebuah lingkaran $L$ serta sembarang garis yang melalui $P\left(x_{1}, y_{1}\right)$ dan memotong lingkaran di $A, B, C$, dan seterusnya maka kuasa titik $P\left(x_{1}, y_{1}\right)$ terhadap lingkaran $L$ adalah perkalian panjang $P A$ dengan $P A^{\prime}$ atau

$$
K_{p}=P O^{2}=P A \cdot P A^{\prime}=P B \cdot P B^{\prime}=P C \cdot P C^{\prime}
$$

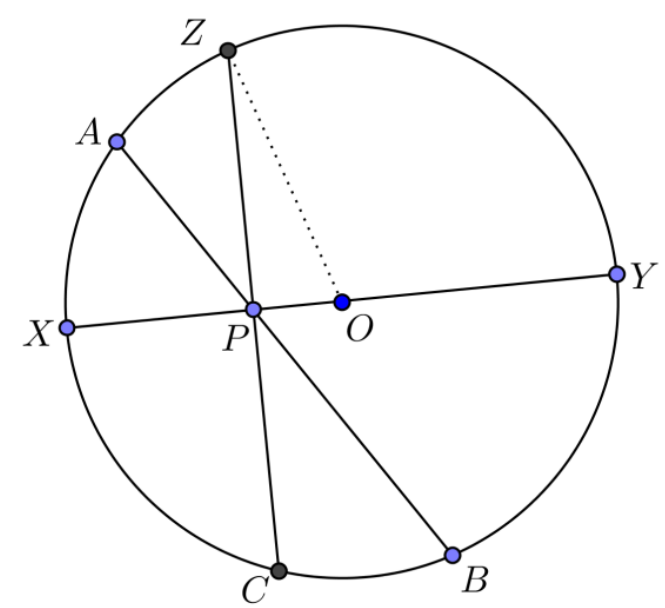

Gambar 2: Kuasa titik di dalam lingkaran

Misalkan titik $P\left(x_{1}, y_{1}\right)$ pada Gambar 2 berada di dalam lingkaran $L$ maka berlaku

$$
K_{p}=-\left(P Z^{2}\right)=-P X \cdot P Y=-P A \cdot P B
$$

Lingkaran merupakan salah satu hasil irisan kerucut. Irisan kerucut adalah perpotongan bidang lengkung kerucut lingkaran tegak dengan bidang datar. Hasil irisan kerucut lainnya yaitu elips, parabola, dan hiperbola. Berdasarkan teori kuasa titik terhadap lingkaran maka penulis tertarik untuk mengembangkan pada salah satu irisan kerucut lainnya yaitu hiperbola.

\section{Landasan Teori}

Misalkan $O$ titik pusat suatu lingkaran dan $R$ adalah jari-jari lingkaran, maka kuasa titik $P$ terhadap lingkaran tersebut didefinisikan $O P^{2}-R^{2}$.

Kuasa titik $P$ adalah $O P^{2}-R^{2}$. Berdasarkan Gambar 2.3 terlihat bahwa $P T^{2}=O P^{2}-O T^{2}$. Misalkan $K_{P}$ adalah kuasa titik dari titik $P$ terhadap lingkaran maka $K_{P}=P T^{2}=O P^{2}-O T^{2}=P A P B$. 


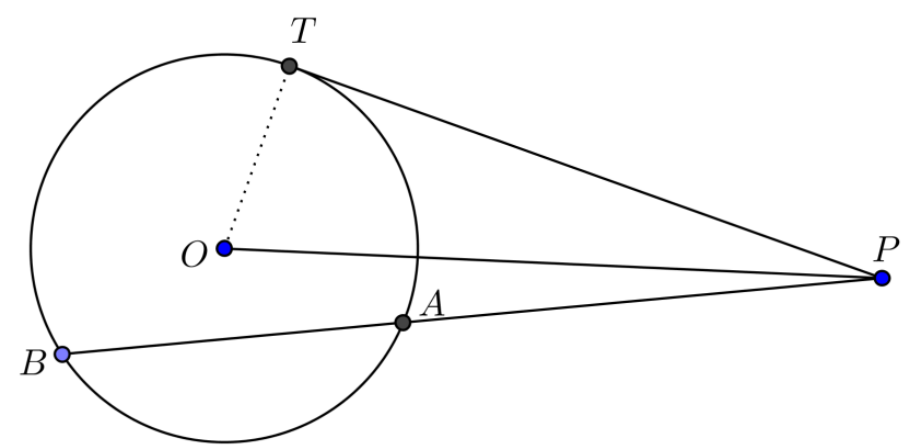

Gambar 3: Kuasa titik di luar lingkaran

Jika diketahui titik $P$ yang berada di dalam lingkaran yang berpusat di $O$ dan sebarang garis yang melalui titik $P$ dan memotong lingkaran di titik $A$ dan titik $B$, maka akan dibuktikan bahwa kuasa titik $P\left(K_{P}\right)$ terhadap lingkaran adalah

$$
K_{P}=-\left(P Z^{2}\right)=-P A P B .
$$

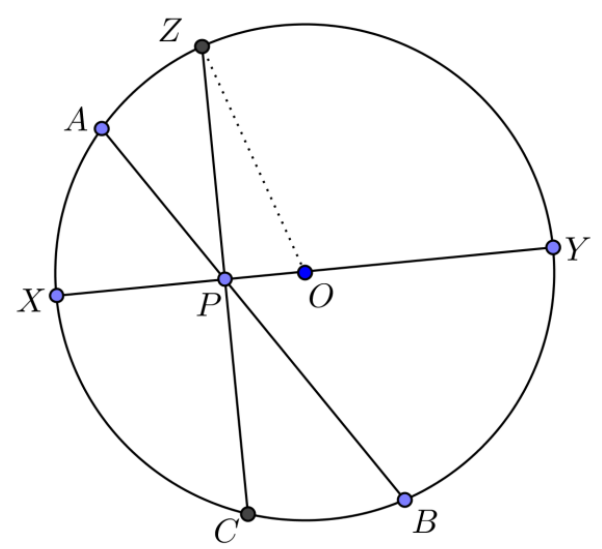

Gambar 4: Kuasa titik di dalam lingkaran

Bukti Perhatikan $\triangle Z P O$ dan $\triangle C P O$, garis $X Y$ dan garis $C Z$ berpotongan tegak lurus di titik $P$. Berdasarkan dalil Pythagoras berlaku

$$
P Z^{2}=R^{2}-O P^{2}=P C^{2}
$$

akibatnya

$$
P Z=P C
$$

Selanjutnya perhatikan $\triangle P A Z$ dan $\triangle P C B$

$$
\begin{aligned}
& \angle A P Z=\angle C P B, \text { karena bertolak belakang } \\
& \angle P Z A=\angle P B C, \text { karena menghadap busur } A C,
\end{aligned}
$$

karena pada $\triangle P A Z$ dan $\triangle P C B$ terdapat sudut yang berkorespondensi kongkruen maka $\triangle P A Z \sim \triangle P C B$ mengakibatkan proporsional sisi 


$$
\begin{gathered}
\frac{P A}{P C}=\frac{P Z}{P B} \\
P Z . P C=P A . P B,
\end{gathered}
$$

dengan mensubtitusikan persamaan (2) ke persamaan (3) maka diperoleh

$$
P Z^{2}=P A P B
$$

Nilai kuasa titik $P$ yang berada di dalam lingkaran dapat ditentukan dengan mensubstitusikan persamaan (4) ke persamaan (1) maka diperoleh

$$
K_{P}=-\left(P Z^{2}\right)=-P A P B
$$

Berdasarkan teori kuasa titik terhadap lingkaran diketahui bahwa kuasa titik terhadap lingkaran merupakan kuadrat panjang garis singgung suatu titik dengan lingkaran dimana garis singgung tersebut tegak lurus terhadap jari-jari lingkaran. Akan tetapi, pada hiperbola garis singgung dari suatu titik tidak tegak lurus terhadap latus rectum dan tidak selalu tegak lurus terhadap sumbu simetri. Oleh karena garis singgung dari suatu titik di luar hiperbola tidak tegak lurus terhadap latus rectum hiperbola dan tidak selalu tegak lurus terhadap sumbu simetri maka pada hiperbola dinamakan sebagai semi kuasa titik karena tidak memenuhi syarat tegak lurus pada konsep kuasa titik.

\section{Hasil dan Pembahasan}

\subsection{Menentukan Semi Kuasa Titik di Sebelah Kanan Latus Rectum}

Misalkan titik $P\left(x_{1}, y_{1}\right)$ pada Gambar 5 terletak di sebelah kanan latus rectum hiperbola. Konstruksi garis dari titik $P\left(x_{1}, y_{1}\right)$ ke titik fokus. Tarik garis dari titik fokus dan memotong hiperbola misalkan di titik $C\left(x_{2}, y_{2}\right)$ dan $D\left(x_{3}, y_{3}\right)$ sehingga garis $P C$ dan $P D$ tegak lurus dengan garis $P F_{2}$. Akan ditentukan koordinat titik $C$ dan titik $D$ dengan $|P C|^{2}$ dan $|P D|^{2}$ merupakan kuasa titik $P\left(x_{1}, y_{1}\right)$ terhadap hiperbola.

Garis $P C$ tegak lurus dengan garis $P F_{2}$. Persamaan garis $P F_{2}$ dapat ditentukan dengan menggunakan konsep persamaan garis melalui dua titik yaitu titik $P\left(x_{1}, y_{1}\right)$ dan titik $F_{2}(c, 0)$, sehingga persamaan garis $P F_{2}$ adalah 


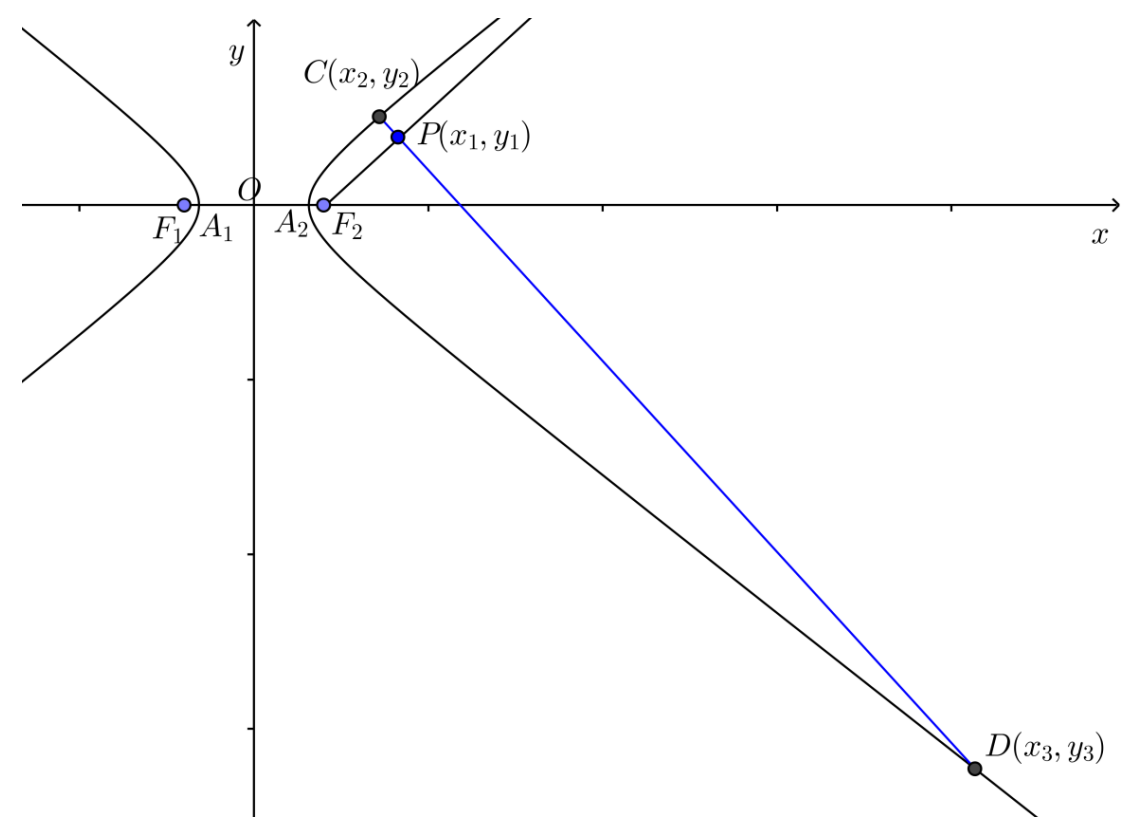

Gambar 5: Kedudukan titik $P\left(x_{1}, y_{1}\right)$ di dalam lengkungan hiperbola

$$
\begin{aligned}
\frac{y-y_{1}}{0-y_{1}} & =\frac{x-x_{1}}{c-x_{1}} \\
y & =\frac{-y_{1}\left(x-x_{1}\right)}{c-x_{1}}+y_{1} \\
y & =y_{1}\left(1-\frac{\left(x-x_{1}\right)}{c-x_{1}}\right) \\
y & =y_{1}\left(\frac{c-x}{c-x_{1}}\right) \\
y & =\frac{y_{1} c}{c-x_{1}}-\frac{y_{1} x}{c-x_{1}} .
\end{aligned}
$$

Berdasarkan persamaan (6) diperoleh gradien $m_{P F}=-\frac{y_{1}}{c-x_{1}}$. Garis $P F_{2}$ tegak lurus garis $P C$ sehingga

$$
\begin{aligned}
{ }^{m_{P F}}{ }^{m_{P C}} & =-1 \\
m_{P C} & =\frac{-1}{-\frac{y_{1}}{c-x_{1}}} \\
m_{P C} & =\frac{c-x_{1}}{y_{1}} .
\end{aligned}
$$


Persamaan garis $P C$ melalui titik $P\left(x_{1}, y_{1}\right)$ bergradien $m_{P C}$ yaitu

$$
\begin{aligned}
& y=\frac{c-x_{1}}{y_{1}}\left(x-x_{1}\right)+y_{1}, \\
& y=\frac{c x-c x_{1}-x_{1} x+x_{1}^{2}+y_{1}^{2}}{y_{1}},
\end{aligned}
$$

substitusikan persamaan (7) ke persamaan hiperbola untuk menentukan titik potong garis $P C$ dengan hiperbola, sehingga diperoleh

$$
\begin{aligned}
& b^{2} x^{2}-a^{2}\left(\frac{c x-c x_{1}-x_{1} x+x_{1}^{2}+y_{1}^{2}}{y_{1}}\right)^{2}=a^{2} b^{2} \\
& b^{2} y_{1}^{2} x^{2}-a^{2}\left(c x-c x_{1}-x_{1} x+x_{1}^{2}+y_{1}^{2}\right)^{2}=a^{2} b^{2} y_{1}^{2} \\
& \left(b^{2} y_{1}^{2}-a^{2} c^{2}+2 a^{2} c x_{1}-a^{2} x_{1}^{2}\right) x^{2}+\left(2 a^{2} c^{2} x_{1}-2 a^{2} c x_{1}^{2}-2 a^{2} c y_{1}^{2}-2 a^{2} c x_{1}^{2}+\right. \\
& \left.2 a^{2} x_{1}^{3}+2 a^{2} x_{1} y_{1}^{2}\right) x+\left(-a^{2} c^{2} x_{1}^{2}+2 a^{2} c x_{1}^{3}+2 a^{2} c x_{1} y_{1}^{2}-a^{2} x_{1}^{4}-2 a^{2} x_{1}^{2} y_{1}^{2}-\right. \\
& \left.a^{2} y_{1}^{4}-a^{2} b^{2} y_{1}^{2}\right)=0 .
\end{aligned}
$$

Nilai $x$ dapat ditentukan dengan menggunakan rumus $a b c$, sehingga diperoleh

$$
x_{2,3}=\frac{-\left(2 a^{2} c^{2} x_{1}-4 a^{2} c x_{1}^{2}-2 a^{2} c y_{1}^{2}+2 a^{2} x_{1}^{3}+2 a^{2} x_{1} y_{1}^{2}\right) \pm \sqrt{D}}{2\left(b^{2} y_{1}^{2}-a^{2} c^{2}+2 a^{2} c x_{1}-a^{2} x_{1}^{2}\right)}
$$

berdasarkan persamaan (8) diperoleh

$$
\begin{aligned}
& a=b^{2} y_{1}^{2}-a^{2} c^{2}+2 a^{2} c x_{1}-a^{2} x_{1}^{2} \\
& b=2 a^{2} c^{2} x_{1}-2 a^{2} c x_{1}^{2}-2 a^{2} c y_{1}^{2}-2 a^{2} c x_{1}^{2}+2 a^{2} x_{1}^{3}+2 a^{2} x_{1} y_{1}^{2} \\
& c=-a^{2} c^{2} x_{1}^{2}+2 a^{2} c x_{1}^{3}+2 a^{2} c x_{1} y_{1}^{2}-a^{2} x_{1}^{4}-2 a^{2} x_{1}^{2} y_{1}^{2}-a^{2} y_{1}^{4}-a^{2} b^{2} y_{1}^{2},
\end{aligned}
$$

dari nilai $a, b$ dan $c$ diperoleh nilai $D$

$$
D=4 a^{2} b^{2}\left[\begin{array}{l}
x_{1}{ }^{2} y_{1}{ }^{2}\left(c^{2}-2 c x_{1}+x_{1}{ }^{2}+2 y_{1}{ }^{2}-a^{2}\right)+x_{1} y_{1}\left(-2 c y_{1}{ }^{3}+2 a^{2} c y_{1}\right)+y_{1}{ }^{2} \\
\left(y_{1}{ }^{4}+b^{2} y_{1}{ }^{2}-a^{2} c^{2}\right)
\end{array}\right]
$$

dengan mensubstitusikan nilai $x$ pada persamaan (9) ke persamaan (7), diperoleh 


$$
y_{2,3}=\left(\frac{c-x_{1}}{y_{1}}\right)\left(\frac{-\left(2 a^{2} c^{2} x_{1}-4 a^{2} c x_{1}^{2}-2 a^{2} c y_{1}^{2}+2 a^{2} x_{1}^{3}+2 a^{2} x_{1} y_{1}^{2}\right) \pm \sqrt{D}}{2\left(b^{2} y_{1}^{2}-a^{2} c^{2}+2 a^{2} c x_{1}-a^{2} x_{1}^{2}\right)}-x_{1}\right)+y_{1} .
$$

Selanjutnya dengan mensubstitusikan nilai $x$ dan $y$ ke koordinat titik $C\left(x_{2}, y_{2}\right)$ dan titik $D\left(x_{3}, y_{3}\right)$ sehingga diperoleh titik singgung $C\left(x_{2}, y_{2}\right)$ dan $D\left(x_{3}, y_{3}\right)$. Semi kuasa titik $P\left(x_{1}, y_{1}\right)$ terhadap hiperbola yaitu kuadrat panjang garis dari titik $P\left(x_{1}, y_{1}\right)$ ke titik $C\left(x_{2}, y_{2}\right)$ dan titik $D\left(x_{3}, y_{3}\right)$, maka dengan menggunakan rumus jarak antara dua titik diperoleh

$$
K_{P_{1}}=|P C|^{2}=\left(x_{2}-x_{1}\right)^{2}+\left(y_{2}-y_{1}\right)^{2}
$$

dan

$$
K_{P_{2}}=|P D|^{2}=\left(x_{3}-x_{1}\right)^{2}+\left(y_{3}-y_{1}\right)^{2}
$$

\subsection{Menentukan Semi Kuasa Titik pada Latus Rectum}

Misalkan titik $P\left(c, y_{1}\right)$ pada Gambar 6 berada pada latus rectum hiperbola, maka semi kuasa titik terhadap hiperbola dapat ditentukan dengan mengkonstruksi garis tegak lurus dari titik $P\left(c, y_{1}\right)$ ke hiperbola dengan titik potong di titik $C\left(x_{2}, y_{1}\right)$. Akan ditentukan koordinat titik $C\left(x_{2}, y_{1}\right)$ dengan $|P C|^{2}$ merupakan semi kuasa titik terhadap hiperbola.

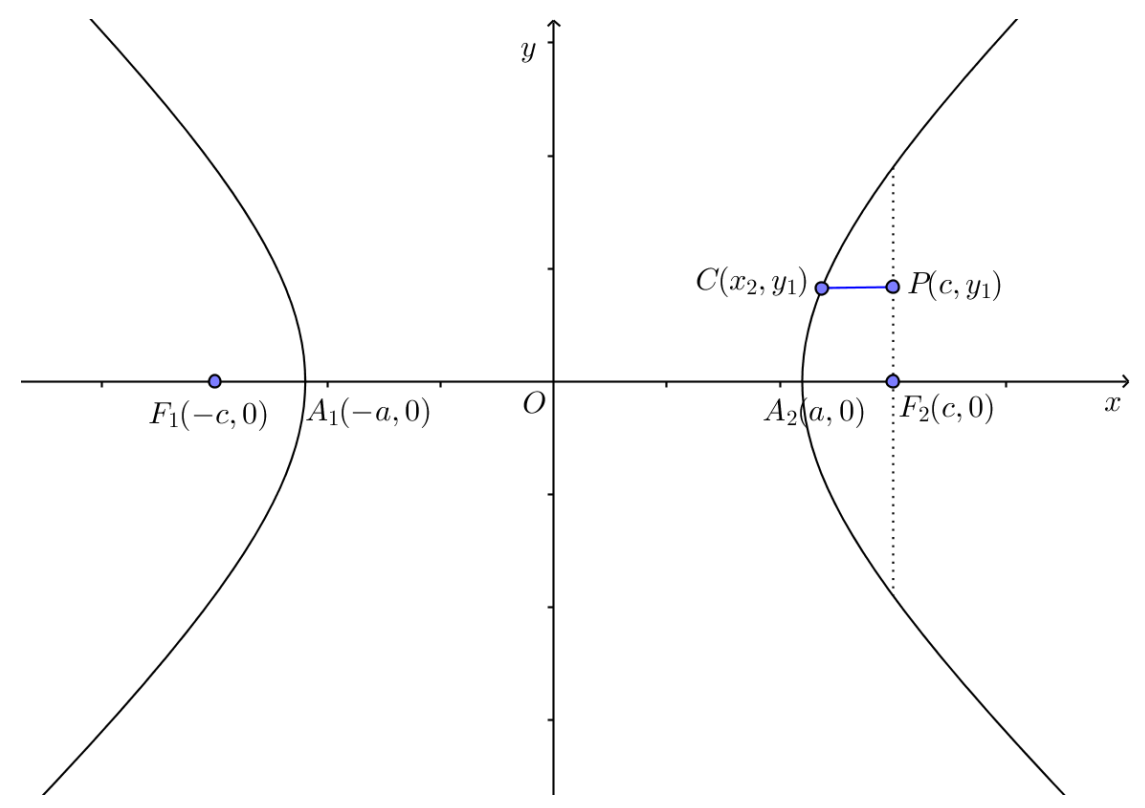

Gambar 6: Kedudukan titik $P\left(c, y_{1}\right)$ pada latus rectum hiperbola 
Persamaan garis dari titik $P\left(c, y_{1}\right)$ ke titik $C\left(x_{2}, y_{1}\right)$ adalah $y=y_{1}$. Titik $C\left(x_{2}, y_{1}\right)$ terletak pada hiperbola $\frac{x^{2}}{a^{2}}-\frac{y^{2}}{b^{2}}=1$ dan pada garis $y=y_{1}$ sehingga berlaku

$$
\begin{aligned}
\frac{x_{2}{ }^{2}}{a^{2}}-\frac{y_{1}{ }^{2}}{b^{2}} & =1 \\
b^{2} x_{2}^{2}-a^{2} y_{1}^{2} & =a^{2} b^{2} \\
x_{2}{ }^{2} & =\frac{a^{2}\left(b^{2}+y_{1}^{2}\right)}{b^{2}} \\
x_{2} & =\frac{a}{b} \sqrt{b^{2}+y_{1}^{2}}
\end{aligned}
$$

dengan mensubstitusikan persamaan (14) ke titik $C\left(x_{2}, y_{1}\right)$ sehingga diperoleh

$$
C\left(\frac{a}{b} \sqrt{b^{2}+y_{1}^{2}}, y_{1}\right)
$$

Jadi nilai semi kuasa titik $C\left(x_{2}, y_{1}\right)$ pada latus rectum hiperbola $\frac{x^{2}}{a^{2}}-\frac{y^{2}}{b^{2}}=1$ adalah

$$
\begin{aligned}
& K_{P}=|P C|^{2}=\left(\frac{a}{b} \sqrt{b^{2}+y_{1}^{2}}-c\right)^{2}+\left(y_{1}-y_{1}\right)^{2} \\
& K_{P}=|P C|^{2}=\left(\frac{a}{b} \sqrt{b^{2}+y_{1}^{2}}-c\right)^{2} .
\end{aligned}
$$

\subsection{Menentukan Semi Kuasa Titik pada Sumbu Simetri didalam Lengkungan Hiperbola}

Misalkan titik $P\left(x_{1}, 0\right)$ pada Gambar 7 terletak pada sumbu simetri, maka persamaan garis melalui titik $P\left(x_{1}, 0\right)$ yaitu

$$
x=x_{1}
$$

Tarik garis dari titik $P\left(x_{1}, 0\right)$ dan memotong hiperbola misalkan di titik $C\left(x_{2}, y_{2}\right)$ dan titik $D\left(x_{3}, y_{3}\right)$ sehingga garis $P C$ dan $P D$ tegak lurus dengan sumbu $x$. 


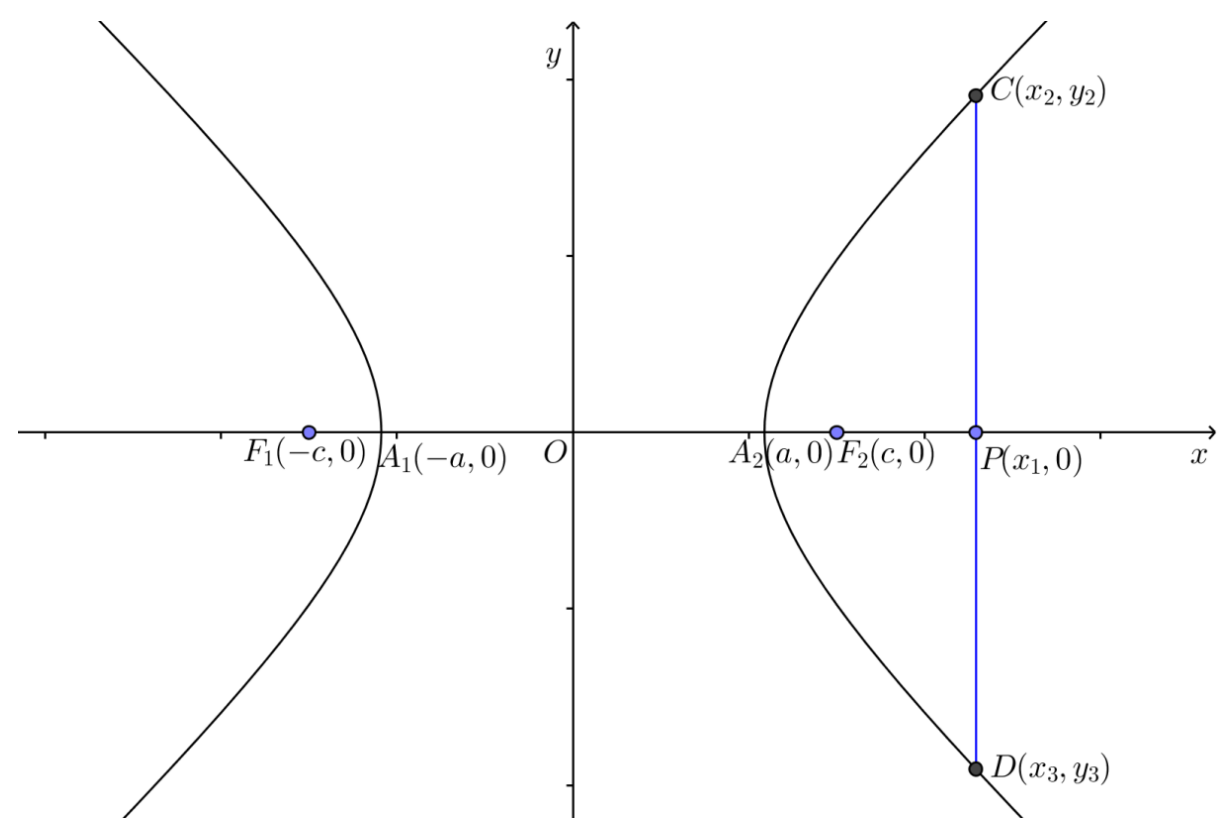

Gambar 7: Kedudukan titik $P\left(x_{1}, 0\right)$ di dalam lengkungan hiperbola

Titik $P\left(x_{1}, 0\right)$, titik $C\left(x_{2}, y_{2}\right)$ dan titik $D\left(x_{3}, y_{3}\right)$ segaris maka berlaku $x_{1}=x_{2}=x_{3}$. Sehingga diperoleh

$$
\begin{aligned}
& b^{2} x_{1}^{2}-a^{2} y^{2}=a^{2} b^{2} \\
& y= \pm \sqrt{\frac{b^{2}}{a^{2}}\left(x_{1}{ }^{2}-a^{2}\right)} .
\end{aligned}
$$

Selanjutnya dari persamaan (16) dan (17) diperoleh koordinat titik

$$
\begin{gathered}
C\left(x_{1}, \sqrt{\frac{b^{2}}{a^{2}}\left(x_{1}^{2}-a^{2}\right)}\right) \\
D\left(x_{1},-\sqrt{\frac{b^{2}}{a^{2}}\left(x_{1}^{2}-a^{2}\right)}\right),
\end{gathered}
$$

sehingga semi kuasa titik $P\left(x_{1}, 0\right)$ dapat ditentukan dengan menentukan kuadrat panjang dari titik $P\left(x_{1}, 0\right)$ ke titik $C\left(x_{2}, y_{2}\right)$ dan titik $D\left(x_{3}, y_{3}\right)$

$$
K_{P}=|P C|^{2}=|P D|^{2}=\left(x_{1}-x_{1}\right)^{2}+\left(\sqrt{\frac{b^{2}}{a^{2}}\left(x_{1}^{2}-a^{2}\right)}-0\right)^{2}
$$




$$
\begin{aligned}
& K_{P}=|P C|^{2}=|P D|^{2}=\left(\sqrt{\frac{b^{2}}{a^{2}}\left(x_{1}^{2}-a^{2}\right)}\right)^{2} \\
& K_{P}=|P C|^{2}=|P D|^{2}=\frac{b^{2}}{a^{2}}\left(x_{1}^{2}-a^{2}\right)
\end{aligned}
$$

\section{Kesimpulan}

Semi kuasa titik $P\left(x_{1}, y_{1}\right)$ yang berada di sebelah kanan atau kiri latus rectum dapat ditentukan dengan menghitung jarak antara titik $P\left(x_{1}, y_{1}\right)$ ke titik potong hiperbola dari garis yang tegak lurus dengan garis yang dikonstruksi oleh titik $P\left(x_{1}, y_{1}\right)$ dan fokus dengan menggunakan persamaan $K_{P_{1}}=|P C|^{2}=\left(x_{2}-x_{1}\right)^{2}+\left(y_{2}-y_{1}\right)^{2}$ dan $K_{P_{2}}=|P D|^{2}=\left(x_{3}-x_{1}\right)^{2}+\left(y_{3}-y_{1}\right)^{2}$.

Kuasa titik $P\left(x_{1}, y_{1}\right)$ yang berada pada latus rectum hiperbola memberikan satu nilai karena hanya terdapat satu garis yang tegak lurus dari titik $P\left(x_{1}, y_{1}\right)$ terhadap hiperbola dan dapat ditentukan dengan persamaan $K_{P}=|P C|^{2}=\left(\frac{a}{b} \sqrt{b^{2}+y_{1}^{2}}-c\right)^{2}$.

Kuasa titik $P\left(x_{1}, y_{1}\right)$ yang berada pada sumbu simetri di dalam lengkungan hiperbola memberikan satu nilai karena dua garis singgung yang ditarik dari titik $P\left(x_{1}, y_{1}\right)$ ke hiperbola mempunyai panjang yang sama dan dapat ditentukan dengan persamaan $K_{P}=|P C|^{2}=|P D|^{2}=\frac{b^{2}}{a^{2}}\left(x_{1}^{2}-a^{2}\right)$

\section{Referensi}

[1] Darsono. Tinjauan Geometri Berdasarkan Filsafat Matematika, $31 \quad$ Maret 2009. http://wwwdarsononmate.blogspot.com/2010/03/filsafat:geometri-31.html.

[2] Eric W. Weisstein, "Hyperbola" From MathWorld-A Wolfram Web Resource, http://mathworld.wolfram.com/Hyperbola.html.

[3] H. S. M. Coxeter dan S. L. Greitzer. (1967). Geometry Revisited. MAA. Washington DC.

[4] H. B. Uno. (2009). Mengelola Kecerdasan dalam Pembelajaran. Bumi Aksara, Jakarta.

[5] L. P. Sicelof, G. Wentworth dan D.E. S,ith. (1992). Analitic Geometry. Ginn and Company. Boston.

[6] Mashadi. (2012). Geometri. Pusbangdik Universitas Riau.

[7] M. Kanginan dan T. Kustendi. (2000). Matematika 3A untuk SMU kelas III. Penerbit Grafindo. Jakarta.

[8] S. Wirodikromo. (2007). Matematika SMA 3 IPA. Penerbit Erlangga. Jakarta.

[9] S. Saragih. (2011). Geometri Analitik Bidang dan Ruang. Pusbangdik Universitas Riau.

[10] S. Rahayuningsih. (2015). Alternatif Menentukan Persamaan Garis Singgung Parabola dan Hiperbola. Tesis Magister. Universitas Riau. 